\title{
La Fundación Rockefeller y la Institución Cultural Española de Buenos Aires frente el exilio republicano español en la Argentina. El caso de Claudio Sánchez Albornoz*
}

\author{
por \\ Miranda Lida ${ }^{1}$ \\ CONICET, Argentina-UDESA
}

El exilio cientifico republicano en las Américas está ampliamente estudiado. En este contexto, el caso del historiador Claudio Sánchez Albornoz resulta excepcional, por la compleja estrategia puesta en marcha para su arribo a la Argentina. Fue apoyado por la Fundación Rockefeller (FR), cuyo papel ha sido poco estudiado. Otro actor que participó fue la Institución Cultural Española de Buenos Aires (ICEBA). Gracias a archivos de la Universidad de Buenos Aires, de la ICEBA (en correspondencia con la FR), podemos reconstruir la trama que lo llevó en la Argentina, con sostenido apoyo por parte de ambas instituciones.

Palabras Clave: Exilio científico republicano español; Argentina; Claudio Sánchez Albornoz; historiografia.

Cómo citar este artículo / Citation: Lida, Miranda, "La Fundación Rockefeller y la Institución Cultural Española de Buenos Aires frente el exilio republicano español en la Argentina. El caso de Claudio Sánchez Albornoz", Revista de Indias, LXXX/279 (Madrid, 2020): 509-539. https://doi.org/10.3989/revindias.2020.015.

\section{INTRODUCCIÓN}

El exilio científico en las Américas producido por el estallido de la guerra civil española y el triunfo del franquismo está ampliamente estudiado en di-

* Este trabajo fue posible gracias a la Cátedra Eulalio Ferrer, 2017, de la Universidad de Cantabria. Investigadora Independiente en el CONICET, Argentina, con lugar de trabajo en la Universidad de San Andrés. Agradezco la lectura y los aportes de Nicolás Sánchez-Albornoz y Clara Lida.

1 mlida@udesa.edu.ar, ORCID iD: https://orcid.org/0000-0001-6788-8356 
ferentes aspectos y geografías. Se conoce el papel desempeñado por los gobiernos de los países receptores y distintos organismos oficiales, nacionales y transnacionales de ayuda a exiliados en México, Estados Unidos, Puerto Rico y en menor medida la Argentina. Así, por ejemplo, han sido estudiadas la labor del Servicio de Evacuación de los Republicanos Españoles (SERE, creado por el gobierno republicano bajo la presidencia de Juan Negrín) y la Junta de Ayuda a los Republicanos Españoles (JARE, impulsada por Indalecio Prieto) y, el papel de algunos gobiernos nacionales (México, Francia, entre otros) y el de organismos internacionales de ayuda humanitaria como el American Friends Service Committee ${ }^{2}$.

En este contexto, el caso del historiador Claudio Sánchez Albornoz, quien fuera un destacado político de la Segunda República Española además de ser un reconocido medievalista que había logrado resonancia en Europa por editar el Anuario de Historia del Derecho español y que en los años treinta encontraremos como director de la sección Instituciones Medievales del Centro de Estudios Históricos de Madrid, es bastante excepcional por la compleja estrategia puesta en marcha a la hora de su salida de España, primero, y de Francia luego, hacia América ${ }^{3}$. No fue asistido por las organizaciones para la ayuda a los refugiados republicanos ni recibió ayuda oficial de ningún gobierno, sino que fue apoyado por la Fundación Rockefeller (FR), cuyo papel ha sido escasamente estudiado en relación con el exilio español ${ }^{4}$. La FR financió su estancia francesa cuando salió de España en 1936, así como también lo acompaño en su exilio en la Argentina, tanto en la Universidad de Cuyo, en la provincia de Mendoza, como en la Universidad de Buenos Aires, más adelante. (No fue el único académico europeo en esta misma condición en la Argentina, puesto que también recibieron apoyo de la FR dos economistas italianos, exiliados de la Italia fascista, acogidos por la Facultad de Ciencias Económicas de la Universidad Nacional de Córdoba: Mario Pugliese y Camilo Viterbo) ${ }^{5}$. Era frecuente que la FR brindara su apoyo a científicos europeos en la década del treinta, en especial, a quienes provenían de países bajo dominio nazi; de hecho, en su gran mayoría los que obtuvieron este tipo de beneficio

2 Alted Vigil y González Martell, 2002. Naranjo Orovio, 1988: 163-195. López Sánchez, 2013. Barona, 2010. Claret Miranda, 2006. García Camarero, 1976. Acerca de las redes solidarias de ayuda a refugiados, véase: Jensen, 2015. Herrerín López, 2012. Alted y Domergue, 2003. Schwarzstein, 2001. Velázquez Hernández, 2014. Mendlesohn, 2002. Para el caso de México: Pagni, 2011. Lida, 1997. Lida, 2009.

3 Guiance, 2011. Carzolio, 2007. Devoto, 2001-2002.

4 Un aporte en este sentido en Sánchez Albornoz, 1994.

5 Terracini, 1989: 335-369. Appleget, 1946. 
pertenecían a las universidades alemanas ${ }^{6}$. Desempeñó una amplia labor de protección y ayuda a científicos y académicos desplazados por los fascismos europeos en la década de 1930, sin embargo, es poco lo que se ha estudiado en relación con el exilio español. Los españoles que recibieron la ayuda de la FR fueron escasos: el médico Severo Ochoa, el politólogo y político Fernando de los Ríos, el filósofo del derecho Alfredo Mendizábal y el jurista José Castillejo, que recibieron asistencia de la Fundación durante su residencia en Estados Unidos; el médico Gustavo Pittaluga, que estuvo por instalarse en Tucumán (Argentina), pero terminó por ir a Cuba y Sánchez Albornoz, el único republicano español que tuvo el respaldo de la fundación norteamericana en la Argentina? ${ }^{7}$.

Otro actor que hizo posible su instalación en la Argentina fue la Institución Cultural Española en Buenos Aires (ICEBA), institución de los inmigrantes españoles que desde su fundación en 1914 hasta 1936 trabajó en colaboración con la Junta de Ampliación de Estudios (JAE) de Madrid para prestigiar y difundir la ciencia española. ${ }^{8}$ La ICEBA tenía vinculaciones con las más importantes casas de altos estudios de la Argentina que fueron decisivas para facilitar su instalación ${ }^{9}$. En lo que respecta al exilio científico republicano en la Argentina, puede afirmarse que se trata del único caso en esta condición: a pesar del drama que supuso la experiencia del exilio Sánchez Albornoz pudo proseguir de inmediato su vida académica. Gracias a distintos archivos de la Universidad de Buenos Aires, de la ICEBA (en correspondencia a su vez con la FR) y de la propia Fundación Rockefeller, es posible reconstruir aquí la trama que hizo posible que Claudio Sánchez Albornoz pudiera radicarse en la Argentina, con prolongado apoyo por parte de la FR que en tres oportunidades lo respaldó, algo bastante excepcional: a su salida de España para instalarse en la Universidad de Burdeos, luego cuando huyó de la Francia ocupada hacia la Argentina, en la Universidad Nacional de Cuyo primero y luego en la de Buenos Aires. Más todavía, la FR lo respaldó incluso una vez que caducó el tiempo de vigencia del subsidio para su instalación en las uni-

6 Gemelli, 2000. Lamberti, 2006. Krohn, 1987.

7 Se considera en este punto solamente a los que recibieron asistencia directa por medio del fondo especial para científicos europeos refugiados establecido por la Fundación Rockefeller en 1933. El número de becas y subsidios concedidos por la FR para instituciones científicas en América Latina y España es sin embargo inabarcable. Además, la FR subsidió distintos proyectos de instituciones estrechamente vinculadas al exilio republicano, como es el caso de El Colegio de México y muchos de sus investigadores. Al respecto, véase Lida y Matesanz, 1990.

8 Naranjo Orovio y Puig Samper, 2007.

9 Naranjo Orovio, 2007. López Sánchez, 2007. Díaz-R. Labajo, 2016. 
versidades argentinas, puesto que continuó durante varios años proporcionándole recursos bajo la forma de fondos para bibliografía, microfilms y otros insumos para desarrollar sus investigaciones.

\section{Salir de Francia, SALIR De Europa}

Cuando se produjo el levantamiento de Franco, Claudio Sánchez Albornoz se encontraba en Portugal, donde ocupaba la cartera diplomática. Salió de Lisboa hacia Francia una vez que el gobierno de Salazar rompió las relaciones diplomáticas que sostenía con el gobierno republicano ${ }^{10}$. Llegó a París con su familia en el otoño de 1936 y se puso en contacto con otros españoles que comenzaban a instalarse en Francia como Ramón Menéndez Pidal. También se entrevistó con historiadores como Marc Bloch, el fundador de la escuela de los Annales y Ferdinand Lot, así como también con el joven hispanista Pierre Vilar. De París la familia pasó pronto a Burdeos donde Claudio Sánchez Albornoz fue invitado por su universidad, que le había conferido el título de Doctor honoris causa en 1934, pero sin muchas garantías de continuidad, por lo cual se apresuró a enviar cartas a diferentes contactos a fin de obtener oportunidades en América. En este contexto, mantuvo un intenso epistolario con Federico Onís quien, instalado en la Universidad de Columbia, Nueva York, desde los años de la primera guerra mundial, fue una pieza clave para encarrilar el exilio de los humanistas republicanos españoles en los Estados Unidos, por sus contactos en el sistema científico norteamericano y también en Puerto Rico y Cuba, donde también trabajó. Así le escribía Sánchez Albornoz a Onís: «tenía empezadas negociaciones en Perú y Argentina y han fracasado [...] ¿No habrá manera de conseguir algunas conferencias en los Estados Unidos para mí?». Las respuestas que recibió no fueron prometedoras, dado que idénticos pedidos llegaban en cantidad en esa misma coyuntura ${ }^{11}$. En 1938, con dificultad, logró viajar a Nueva York, donde tuvo la oportunidad de conversar con Federico Onís, para dirigirse desde ahí a Cuba donde fue invitado a dar conferencias en la Universidad de La Habana; los viajes le permitían no sólo tejer contactos valiosos, sino además reunir algunos ahorros para sostener a su familia.

Ahora bien, a partir de 1938 la Fundación Rockefeller hizo más llevadera su estancia en Francia, puesto que subsidió parte de sus ingresos en la universidad de Burdeos, entre octubre de ese año y septiembre de 1940. Gracias

10 Sánchez Albornoz, 2012.

11 El epistolario entre Claudio Sánchez Albornoz y Onís está en Albert Robatto, 2002. 
al aval de influyentes historiadores como Marc Bloch, le fue concedida la subvención ${ }^{12}$. Para la Fundación Rockefeller, se trató de una decisión que fue juzgada desde un comienzo como «excepcional» dado que el subsidio fue concedido en beneficio de una universidad francesa que, en las vísperas de la Segunda Guerra Mundial, no podía dar muchas garantías de continuidad. Era política de la Fundación Rockefeller exigir a las instituciones que acogieran a los académicos depuestos por los regímenes fascistas que garantizaran al cabo de un período de 2 o 3 años un puesto fijo costeado plenamente por la universidad, pero Burdeos no estaba en condiciones de hacerlo, dado el amenazador contexto internacional. Así, la propia fundación norteamericana a fines de 1938 decidió hacer una excepción con Sánchez Albornoz y aceptó apoyarlo, hubiera o no garantías de continuidad por parte de la universidad. Fue decisiva en este contexto la carta enviada por un importante número de prestigiosos historiadores franceses del Collège de France - entre ellos, Ferdinand Lot - para solicitar que considerara su caso. Mientras tanto, la guerra de España llegaba a su dramático final con la caída de Barcelona y luego con el triunfo de Franco y en Europa, por otro lado, la amenaza de Hitler se cernía cada vez más amenazadora ${ }^{13}$. A medida que transcurría el plazo concedido por el financiamiento de la FR, se hacía imposible regresar a España que, bajo Franco, no cabía esperar que permitiera el retorno del político de la Segunda República que a esa altura del partido ya había sido despojado de su cargo, de acuerdo con la política de depuración llevada a cabo por el nuevo régimen - Sánchez Albornoz evitó por ello viajar vía algún puerto español donde habría corrido el riesgo de ser detenido-. El inicio de la Segunda Guerra Mundial en septiembre de 1939 y la invasión nazi de Francia en mayo de 1940 no dejaban opciones: Burdeos se encontraba en la Francia ocupada de tal modo que quedaba expuesto a ser deportado a la España de Franco.

En este contexto, Sánchez Albornoz preparó el terreno para ir a la Argentina (u otros destinos americanos). Desde Estados Unidos Onís le escribía sin embargo que: «no se podrá hacer nada hasta la terminación de la guerra. Entonces habrá que dar información al organismo que formarán aquí las instituciones científicas acerca de los intelectuales españoles emigrados, sus especialidades, circunstancias, etc.» ${ }^{14}$. Posó sus expectativas entonces en la Argentina. En 1933, Sánchez Albornoz había tenido la oportunidad de viajar a

12 José María López Sánchez, 2013. Acerca de los vínculos de Bloch con Estados Unidos, Fink, 2004.

13 Memorándum de la Oficina en París de la Fundación Rockefeller, 17 de enero de 1939, Archivos de la fundación Rockefeller, Sleepy Hollow, RG 1.1 (FA 386), Box 19, Folder 189.

14 Albert Robatto, 2002: 107. 
la Argentina invitado por la Institución Cultural Española para ejercer la cátedra que desde su fundación en 1914 esta institución sostenía en el marco de la Universidad de Buenos Aires. En aquel momento Sánchez Albornoz era rector de la Universidad Central de Madrid - hoy, Complutense - y acababa de ser nombrado ministro por el gobierno de la Segunda República española, lo cual le dio rango de funcionario de Estado a su visita. Así, pudo entrar en contacto con las elites políticas, funcionarios locales y personalidades conspicuas entre las elites españolas y universitarias en el país. Fue agasajado, entonces, en recepciones oficiales y además brindó conferencias en foros prestigiosos como la Facultad de Filosofía y Letras de la Universidad de Buenos Aires, el Club Español y el Instituto Popular de Conferencias del diario La Prensa. Su estancia de 1933 le permitió preservar el vínculo con la ICEBA, que se volvería valiosísimo en circunstancias adversas como las que atravesó Europa a fines de la década de 1930.

En 1938, por otra parte, asumió la dirección de la ICEBA el catalán Rafael Vehils. Se trata de un empresario que llegó a la Argentina en los años veinte para colaborar en los negocios de Francesc Cambó. En los años treinta, estuvieron volcados a la provisión de energía eléctrica para la ciudad de Buenos Aires a través de la Compañía Hispano Argentina de Electricidad (conocida también como CHADE/ CADE). Cambó y Vehils provenían del movimiento regionalista catalán y además habían colaborado en impulsar distintas iniciativas editoriales de impronta americanista (a través de la Casa de América), así que tenían un desempeño destacado en el campo cultural, cosa que habilitaría a Vehils a postularse a la dirección de ICEBA ${ }^{15}$. Su designación fue aplaudida por personalidades de la cultura española en la Argentina como fue el caso del lingüista Amado Alonso que le escribió para decirle que «todos debemos agradecer que en momentos tan difíciles como los actuales hayan aceptado el gobierno de la gloriosa Institución Cultural hombres de tan probado patriotismo y amor a la cultura ${ }^{16}$. Desde ese lugar, el empresario llevó adelante una intensa política cultural destinada a fortalecer los vínculos entre la ciencia española y las universidades argentinas. El contexto proporcionado por la guerra civil y el franquismo para las instituciones científicas españolas brindó un escenario difícil en el que por un lado la institución comunitaria procuró mantener una actitud lo más neutral posible, a pesar de la guerra en curso, dado que la ICEBA no quería quedar mal posicionada ante el gobierno

15 Dalla-Corte Caballero, 2005. Lucci, 2016.

16 Carta de Amado Alonso a Rafael Vehils, Buenos Aires, 11 de mayo de 1938, Archivo de la Institución Cultural Española de Buenos Aires (ICEBA), Residencia de Estudiantes, Madrid, Correspondencia recibida 1, legajo 6, foto 17 . 
español que surgiera victorioso de la contienda; debía, por tanto, moverse con cautela.

Por otro lado, procuró en la medida de lo posible abrir puertas para que las instituciones científicas argentinas y la propia ICEBA pudieran absorber científicos españoles de todas las disciplinas que quedaron a la deriva por la guerra civil, ofreciéndoles alguna salida a su desesperada situación: sin trabajo, probablemente sin casa debido a un forzoso exilio, con familia dispersa en Europa, sin perspectivas en un contexto europeo cada vez más difícil. La ICEBA tenía una larga trayectoria de colaboración con las universidades argentinas, puesto que sostenía una cátedra que desde su fundación en 1914 habían ocupado importantes personalidades de la ciencia y la cultura españolas: Ramón Menéndez Pidal, José Ortega y Gasset, Pío del Río Hortega, Adolfo Posada, Julio Rey Pastor, Blas Cabrera, Augusto Pi y Suñer, entre otros ${ }^{17}$. A través de esta iniciativa, la ICEBA estableció fuertes vínculos con la Universidad de Buenos Aires y otras universidades argentinas, dado que los invitados solían viajar a dar conferencias a otras universidades además de Buenos Aires, como La Plata, Córdoba o Tucumán. La ICEBA era pues una institución clave para apoyar la labor científica de los españoles en la Argentina a la que Sánchez Albornoz no podía dejar de recurrir. Para fortalecer su influencia en el ámbito universitario, las autoridades de la ICEBA dispusieron en 1938 la creación de un consejo técnico compuesto por profesores de las distintas facultades de la Universidad de Buenos Aires que asesorarían en las eventuales contrataciones que se hicieran de científicos españoles: el consejo, compuesto, entre otros nombres, por los médicos Bernardo Houssay y José Arce, los historiadores Emilio Ravignani y Ricardo Levene, Amado Alonso, entre otros, con el aval del rector de la Universidad de Buenos Aires, Vicente Gallo, a la sazón, abogado de la empresa CHADE que presidía Cambó ${ }^{18}$. Cuando en 1938 Rafael Vehils se hizo cargo de la dirección de ICEBA, expresó su preocupación por la situación de los científicos españoles dispersos por la guerra civil y desarrolló incontables gestiones para intentar llevar a la Argentina a los más prestigiosos científicos españoles a la deriva ${ }^{19}$.

Con Sánchez Albornoz, las tratativas para un eventual viaje a la Argentina se agilizaron en 1939. En febrero, el historiador le escribía a Vehils que «su carta me ofrece un rayo de esperanza [...] No es nunca grato confesar

17 Fernández Terán y González Redondo, 2010.

18 Resolución del rector Vicente Gallo, Buenos Aires, 29 de diciembre de 1938, copia en Archivo de ICEBA, Residencia de Estudiantes, Madrid, Correspondencia recibida 1, legajo 6, foto 332. Acerca de la empresa CHADE, véase De Riquer, 2016.

19 López Sánchez, 2013. 
dificultades económicas, pero apartado de toda actividad política desde mi salida de Lisboa en octubre del 36, vivo desde entonces de mi trabajo y la Historia Medieval no es precisamente un buen negocio» ${ }^{20}$. De viaje en Europa ese año, Vehils se encontró con Sánchez Albornoz en Francia, donde se había concentrado buena parte del exilio científico español. En los meses subsiguientes, el intercambio epistolar con Vehils se hizo asiduo; Sánchez Albornoz compartió con él expectativas, proyectos e inquietudes, además de proponerle cursos y publicaciones para presentar en un eventual viaje a Buenos Aires que preparaba para los meses subsiguientes. Le hizo saber además que su situación en Francia era precaria dado que la subvención de la Rockefeller era temporal. Y con la guerra que se avecinaba, la perspectiva de permanecer en Europa se tornaba insostenible, de ahí que Sánchez Albornoz estuviera considerando la idea de aprovechar los meses del verano septentrional para viajar a la Argentina, a fin de abrirse puertas. La propuesta de cursos que le envió a Vehils en 1939 incluía toda una agenda de trabajo que en parte anunciaba su labor historiográfica de años subsiguientes y en parte recogía, desde luego, temas en los que ya venía trabajando desde sus primeras incursiones en la investigación:

Apenas había U. llegado a la primera esquina cuando había encontrado un tema capaz, a lo que creo, de interesar: El régimen agrario y la cuestión social en la monarquía castellana durante la Edad Media. ¿Qué le parece? Puedo hacer sobre tal asunto un curso ceñido: erudito y documentado, y a la par interesante, porque me permitirá trazar una proyección hacia el presente al estudiar las consecuencias de tal régimen agrario y de tal organización social de la Castilla del Medievo, madre de América. [...] Creo tal asunto más interesante que Los orígenes de la reconquista. [...]. Lo haré con abundancia de textos y procurando saltar las fronteras de Castilla y aun de España.

Para la labor de seminario y de investigación le ofrezco dos enunciados, uno de historia de las instituciones y otro de historia política: A: Orígenes de las Cortes de Castilla; B: Cómo se hace la historia de un reinado. Alfonso II o III.

Me llevaré mis documentos y haré un seminario a la alemana, ante los que sientan interés por acometer conmigo una vez a la semana la labor de investigación. $[\ldots]$

Y como conozco el paño y sé que habré de hacer algunas conferencias para el gran público he pensado y le propongo estos tres temas enlazados para un cursillo: El enigma de España; España clave de la Edad media; La Edad Media clave de España. Quizá deba desdoblar la tercera en dos y en ese caso haría una cuarta: Proyección medieval en la España Moderna. Prepararé también algunas otras conferen-

20 Carta de Claudio Sánchez Albornoz a Rafael Vehils, Bordeaux, 16 de febrero de 1939, Archivo de ICEBA, Residencia de Estudiantes, Madrid, Correspondencia recibida 2, legajo 7 , foto 593 . 
cias por si recibo invitaciones de alguna institución o universidad argentina. Podría si lo desean hacer algo así. Castilla que hizo a España, en varias conferencias.

Dígame qué le parece mi propuesta. Un curso universitario de dos clases semanales, una sesión de seminario a la semana y las 3 conferencias públicas ${ }^{21}$.

La propuesta, concienzuda y con conocimiento del terreno, de ahí la variada gama de actividades que presentaba, desde conferencias para público amplio hasta seminarios especializados de investigación, se completaba con la oferta de materiales para publicar un libro en la Argentina que Sánchez Albornoz ponía a disposición de Vehils.

un índice de la Historia de Asturias. Ya le decía ayer que tengo mucho material gráfico [...] Será un libro de unas seiscientas páginas. M. Pidal lo apadrinó y lo conoce en parte. Puedo enviarle también un índice del otro libro. Las fuentes árabes del de Asturias son iguales que las del siglo VIII, pero claro que es diferente el punto de vista y más sucinto el estudio de ellas para la historia asturiana que para la historia árabe ${ }^{22}$.

La perspectiva de publicar en la Argentina era tal vez el atractivo más importante, dado el papel central que la industria editorial argentina comenzaba a adquirir en Hispanoamérica luego de que la guerra civil española redundara en el exilio de importantes editores que se radicaron en Buenos Aires como Gonzalo Losada, que fundó la casa homónima, que sería importante canal de expresión del exilio republicano ${ }^{23}$. Así, le escribía a Vehils que no aspiraba a cobrar derechos por sus publicaciones: «mis pretensiones de autor serán mínimas o nulas. Deseo ante todo que se publiquen mis cosas $\gg^{24}$. En Burdeos le habían prometido la posibilidad de publicar, pero dado que su cátedra dependía más de la FR que de la propia universidad francesa, vio cada vez con menos expectativas que se hiciera realidad.

Vehils vaciló antes de darle el visto bueno: dudó de la pertinencia del tema principal para su curso en Buenos Aires: «me parecen excelentes [cursos] siempre que en el relativo al régimen agrario no trate nada que se relacione con la actualidad». El temor de Vehils era muy claro: que de la historia me-

21 Carta de Claudio Sánchez Albornoz a Rafael Vehils, Bordeaux, 12 de marzo de 1939, Archivo de ICEBA, Residencia de Estudiantes, Madrid, Correspondencia recibida 2, legajo 7 , fotos 594-597. Subrayados en el original.

22 Carta de Claudio Sánchez Albornoz a Rafael Vehils, Bordeaux, 14 de marzo de 1939, Archivo de ICEBA, Residencia de Estudiantes, Madrid, Correspondencia recibida 2, legajo 7, fotos 598-599.

23 De Diego, 2015.

24 Carta de C. Sánchez Albornoz a Rafael Vehils, 19 de marzo de 1939, Archivo de ICEBA, Residencia de Estudiantes, Madrid, Correspondencia recibida 2, legajo 7, fotos 600. 
dieval se hicieran extrapolaciones que llevaran a la historia contemporánea y desembocaran en debates políticos, situación que quería evitar en un contexto tan polarizado intelectualmente como el que se vivía en la Argentina de los años de la guerra civil española y de la segunda guerra mundial. Al fin y al cabo, la reforma agraria había formado parte de la agenda de la Segunda República, con muchas resistencias por parte de sectores conservadores que, más tarde, apoyarían a Franco. Sánchez Albornoz captó rápidamente el punto y le respondió con calma, pero con determinación, puesto que no silenció un cierto malestar con la discusión:

No me propongo hacer sino historia e historia medieval de modo exclusivo. Cuando le decía que el tema en cuestión me permitiría acercarme al presente indicaba simplemente que al desarrollarlo podría suscitar el interés de las gentes de hoy, llegar a su atención, pues para el hombre contemporáneo ha de tener actualidad el conocimiento de cómo se han forjado los regímenes agrarios y las organizaciones sociales de otras épocas. [...]

Quiero creer que en las suyas [ $v$ g., palabras] no habrá a la inversa ni sombra de propósito delimitar la libertad de criterio científico con que todo profesor ha de moverse al exponer sus tesis históricas, físicas o filosóficas... ¿No es eso? Claro que la historia de la vida medieval [...] es tema poco candente para suscitar dificultades de ese orden y yo soy sobradamente frío para no buscar en la cátedra sino la ciencia pura $^{25}$.

En un contexto signado por el inminente triunfo de Franco, Vehils mantuvo una posición extremadamente cauta cuando se trataba de llevar a la Argentina intelectuales españoles exiliados; solía exigir una suerte de declaración de apoliticidad, o al menos un cierto compromiso de «neutralidad» no siempre fácil de cumplir. Vehils tuvo suspicacias con respecto a Sánchez Albornoz, de hecho, en carta desde Europa a uno de sus compañeros en la dirección de ICEBA le decía que: «Sánchez Albornoz quisiera ser de la "misión". Pero no me parece político. Lo exploraré» ${ }^{26}$. Vehils no quería comprometerse con él en un principio; el propósito de su viaje a Europa de 1939 era llevar a Buenos Aires a Ramón Menéndez Pidal, que había presidido el Centro de Estudios Históricos y la JAE antes de la guerra y estaba refugiado en París, puesto que había sido quien inauguró la cátedra de ICEBA en Buenos Aires. En 1939 se cumplían los 25 años de ICEBA y Vehils esperaba festejarlo con la presencia de grandes figuras de la ciencia española, en un

25 Carta de C. Sánchez Albornoz a Rafael Vehils, 30 de marzo de 1939, Archivo de ICEBA, Residencia de Estudiantes, Madrid, Correspondencia recibida 2, legajo 7, fotos 603-4.

26 Carta de Rafael Vehils a G. Cano, París, 1 de marzo [de 1939], Archivo de ICEBA Residencia de Estudiantes, Madrid, Correspondencia recibida 1, legajo 6, foto 334. 
momento donde, además, tenía la expectativa de que el fin de la guerra civil permitiría recomponer relaciones con España (no rehuía establecer tratos diplomáticos con el gobierno franquista), así como también transmitir un clima de concordia en la comunidad española en la Argentina. En este contexto, invitar a alguien del perfil de Sánchez Albornoz, que había sido parte del gobierno republicano, a un evento oficial de ICEBA, de impacto diplomático en las relaciones con España, era para Vehils un gesto por demás imprudente. Por ello, una vez que Menéndez Pidal rechazó la invitación, Vehils se decantó por el físico Julio Palacios, que acababa de ser designado vicerrector de la Universidad Central y vicepresidente del Instituto de España —el sucedáneo de la JAE durante el régimen de Franco — ${ }^{27}$. Fue entonces que Vehils le escribió al historiador para decirle que se aplazaría su eventual viaje a la Argentina puesto que no había consenso en la comisión directiva de ICEBA. No sin razón, Sánchez Albornoz advirtió que algo pasaba y contestó: "si he de decirle la verdad atribuía sus aplazamientos a algún veto nacionalista que se interponía entre su deseo sincero de llevarme y mi viaje» ${ }^{28}$. La relación, evidentemente, se enfrió. Pero retomaron contacto en agosto de 1939, cuando ya era una decisión tomada que ICEBA no invitaría a Sánchez Albornoz a Buenos Aires para dicha celebración. El historiador comprendió la situación y le escribió a Vehils que «ha encontrado U. una fórmula feliz para salvar las dificultades [...] dada mi significación política. Siempre hubiese preferido sin embargo ir a Buenos Aires porque confiaba en obtener un puesto en la Argentina» ${ }^{29}$.

La difícil situación internacional reavivó el anhelo por ir a la Argentina: el 1 de septiembre dio inicio la Segunda Guerra Mundial. Se ingresó en un compás de espera, sin embargo, porque los meses finales de 1939 Europa se sumió en la pasividad del drôle de guerre hasta la primavera de 1940 cuando Hitler arremetió con una seguidilla de agresivas campañas militares que culminarían con la caída de París. En este contexto, Francia entró en una veloz carrera armamentista que redundó en sucesivos recortes de presupuesto universitario que perjudicaron a Sánchez Albornoz. Si la universidad de Burdeos le recortaba sus ingresos, la FR podía a su vez amenazar

27 Sesión del 25 de julio de 1939, Libro de Actas 2 A de ICEBA, 1937-1940, folios $103-$ 104, Archivo de ICEBA, Residencia de Estudiantes, Madrid.

28 Carta de Claudio Sánchez Albornoz a Rafael Vehils, Bordeaux, 16 de mayo de 1939, Archivo de ICEBA, Residencia de Estudiantes, Madrid, Correspondencia recibida 2, legajo 7, foto 616 .

29 Carta de Claudio Sánchez Albornoz a Rafael Vehils, Bordeaux, 22 de agosto de 1939, Archivo de ICEBA, Residencia de Estudiantes, Madrid, Correspondencia recibida 2, legajo 7 , foto 625 . 
con interrumpir sus pagos dado que su compromiso era subvencionar una porción de su sueldo.

Mi situación me obligará a aceptar lo que Us. me ofrezcan. Hoy le escribo no sólo para repetirle la carta sino para rogarle que de acuerdo con los amigos de esa: [Ricardo] Levene, [Luis] Méndez Calzada, [Enrique] Larreta y cuantos pueda U. sumar en su empresa procure lograr algo para mí en esa [v. g., Buenos Aires]. Cuando U. tuvo la gentileza de venir a verme a Burdeos le referí como la Universidad, a medias con la Fundación Rockefeller, me habían ofrecido dos años de trabajo, hasta fin de 1940; pero ayer me comunicó el decano de la Facultad de Letras que con ocasión de las economías a que con motivo de la guerra se ven forzados no pueden mantener su compromiso. Me quedo pues sin trabajo y en situación muy difícil y con una numerosa familia a mi cargo. Esta circunstancia me obliga a molestarle para que intente con los amigos señalados y acaso también con [Marcelo T. de] Alvear y con el Senador [Alfredo] Palacios que quizá ayuden asimismo, lograr algo para mí en esas universidades de Buenos Aires y La Plata ${ }^{30}$.

Lo que Sánchez Albornoz solicitaba no era sencillo. Su situación obligaba a buscar alternativas, pero sin sacrificar el acuerdo con la FR; así, la única solución sería intentar trasladar el acuerdo vigente con la FR a una institución argentina, pero eso implicaba en la práctica dos cuestiones: por un lado, la necesidad de obtener el consentimiento previo de las autoridades universitarias francesas; por el otro, los consabidos apoyos en la Argentina, difíciles de gestionar desde Burdeos. Sin duda fue de mucha ayuda una nueva carta enviada en octubre de 1939 por los colegas del Collège de France dirigida a la FR, con el expreso pedido de que la fundación no abandonara su auxilio a Sánchez Albornoz, aun cuando la Universidad de Burdeos no pudiera sostener sus ingresos ${ }^{31}$. Se hizo necesario mover influencias cuanto antes dado lo amenazante de la situación europea. Por ello Sánchez Albornoz le imploraba a Vehils que hablara con profesores universitarios como el historiador Ricardo Levene, personas influyentes en las elites españolas como Luis Méndez Calzada y políticos como el radical Alvear y el socialista Palacios. En este punto, el papel de Vehils sería crucial porque tenía contactos en las universidades, en el Estado y la política, así como también en el mundo empresarial de la Argentina. Sánchez Albornoz no concebía la idea de pasar la guerra en Europa, como así tampoco regresar a España, donde no podía esperar encontrar un escenario amable para un antiguo ministro de la Segunda República, por

30 Carta de Claudio Sánchez Albornoz a Rafael Vehils, s/d, Archivo de ICEBA, Residencia de Estudiantes, Madrid, Correspondencia recibida 2, legajo 7, foto 624.

31 Carta colectiva firmada por Ferdinand Lot et al., París, 13 de octubre de 1939, Archivos de la Fundación Rockefeller, Sleepy Hollow, RG 1.1 (FA 386), Box 19, Folder 189. 
tanto, la única opción razonable que quedaba en su horizonte era ir a la Argentina. En este mismo sentido, Federico Onís le escribió desde Estados Unidos que: «Creo que la Argentina le ofrecerá mayores facilidades que los Estados Unidos para resolver su situación. Ahí tiene usted la ventaja del idioma y de ser conocido por todo el mundo. Aquí, con la afluencia de refugiados de todos los países de Europa la situación de los españoles que aquí se encuentran se hace cada vez más difícil» $»^{32}$. No desdeñó otras posibilidades en América Latina - en especial en $\mathrm{Cuba-}$ - pero sus preferencias estuvieron depositadas en la Argentina, no solo porque podría allí aspirar a puestos en instituciones prestigiosas, sino también porque Buenos Aires ofrecía la posibilidad de acceder a colaborar en los principales diarios como La Nación o La Prensa, así como también le facilitaría contactos con las casas editoriales. Valoraba igualmente las instituciones educativas de la Argentina como posibilidad para los estudios de sus hijos a los que quería educar en lengua española, de ahí que no le interesara radicarse en los Estados Unidos. La respuesta de Vehils, ante lo desesperado de su situación en Francia, no tardó en llegar, si bien era de carácter condicional, puesto que había que evaluar la estrategia a implementar para continuar con el acuerdo con la FR. Como ya había advertido en su carta el propio Sánchez Albornoz, la posibilidad de prorrogarlo dependería de los respaldos institucionales:

No creo posible que los Rockefeller se dirijan a la Cultural ofreciendo esto o lo otro. Nunca lo hacen en casos personales. Aquí [Francia] fue la Universidad la que solicitó la ayuda de la delegación de Rockefeller en París para costear la mitad de mi sueldo. Al principio se negaron, arguyendo que sólo concedían ayudas parecidas cuando la institución que la solicitaba se comprometía a sostener al profesor en exilio por tres años y a otorgarle después un puesto más o menos permanente, y no podía ser este el caso en Francia. Añadían que, si alguna institución americana les proponía un arreglo parecido, estaban dispuestos a otorgar la subvención. [...] Intervinieron los medievalistas e hispanistas de la Sorbona y del Instituto de Francia [...] y entonces los Rockefeller accedieron, siempre que la universidad [de Burdeos] se comprometiera a costear la mitad de mi sueldo por dos años [...] cuando la guerra viene a interrumpir el compromiso de la Universidad ${ }^{33}$.

Una vez explicada la situación, Vehils concluyó que para ir a Buenos Aires desde Francia sería necesaria una compleja negociación:

32 Carta de Federico Onís a Claudio Sánchez Albornoz, 28 de abril de 1941, Albert Robatto, 2002: 109.

33 Carta de Claudio Sánchez Albornoz a Rafael Vehils, Bordeaux, 17 de octubre de 1939, Archivo de ICEBA, Residencia de Estudiantes, Madrid, Correspondencia recibida 2, legajo 7 , foto 635 . 
No es posible que nosotros tomemos la iniciativa de dirigirnos al instituto Rockefeller. En cambio, si la Universidad de Buenos Aires (Facultad de Derecho) o la Academia Nacional de la Historia, o nosotros mismos, recibiéramos de Rockefeller la oferta de costear el $50 \%$ de sus honorarios a abonar a Ud. para una actuación docente de un año, por de pronto creo que yo podría combinar las cosas para facilitarle el otro $50 \%$. Ahora bien, las cátedras aquí se remuneran con $\$ 400$ mensuales. Con esta suma no podría Ud. vivir. Con 1000 mensuales creo que Ud. podría hacerlo, bien que modestamente. Por eso indiqué yo que el aporte eventual de Rockefeller debiera ser de 500. Muévase Ud. con sus amigos de esa Universidad y vea de lograr esa oferta que es para mí, repito, el indispensable punto de apoyo para poder servirle en la forma cordial en que le desea éste su amigo ${ }^{34}$.

Corolario: era necesario actuar rápido en distintos frentes, Francia, Nueva York, Buenos Aires... en un contexto agravado por la coyuntura mundial. La caída de Francia entre mayo y junio de 1940 en manos de Hitler precipitó los acontecimientos que llevarían a Sánchez Albornoz a la Argentina a fines de ese mismo año. En este contexto, Vehils acarició la idea de que la propia ICEBA creara una cátedra de «Historia de las instituciones españolas en el seno de la Universidad de Buenos Aires», costeada por la institución comunitaria de los españoles. Sin embargo, la ICEBA requería de todos modos la anuencia de las autoridades universitarias de Buenos Aires, algo difícil de obtener en una universidad que, desde mediados de los años treinta, había cerrado la posibilidad de que sus cargos estuvieran en manos de extranjeros. El ingreso a la Universidad de Buenos Aires, por ende, no sería fácil ni para Sánchez Albornoz ni para ningún otro académico refugiado en la Argentina. De ahí que se hiciera necesario encontrar alternativas.

La solución llegó desde los Andes: Sánchez Albornoz no sería contratado por la Universidad de Buenos Aires, como anhelaba, sino por una universidad periférica: la Universidad Nacional de Cuyo, fundada en 1939 en la ciudad de Mendoza. Desde su fundación, el abogado Edmundo Correas fue el rector encargado de organizarla, quien le imprimió una gestión enérgica con la intención de darle una composición que priorizara la investigación y la excelencia, abriendo la universidad al mundo, por medio de la contratación de profesores extranjeros expulsados de Europa por el franquismo en España y el fascismo y el nazismo en general. Si bien era un funcionario conocido por su pertenencia a círculos conservadores, en una época de hegemonía de gobiernos conservadores en la Argentina, Correas fue lo suficientemente cosmopolita y flexible como para hacer posible que la universidad cuyana se volviera

34 Carta de Rafael Vehils a Claudio Sánchez Albornoz, Buenos Aires, 21 de octubre de 1939, Archivo de ICEBA, Residencia de Estudiantes, Madrid, Correspondencia recibida 2, legajo 7 , foto 639 . 
una suerte de experimento en el cual convivían profesores de distintas nacionalidad, refugiados por razones políticas, o bien, aunque solo fuere, por escapar de los horrores de la guerra europea: entre otros, pasaron por Mendoza el filólogo catalán Joan Corominas, su hermano, el matemático Ernesto Corominas, el matemático catalán Juan Balanzat, el economista alemán Carlos Becker y el artista plástico francés Jean Driesbach ${ }^{35}$.

Cada invitado demandaba largas gestiones a través de cartas de recomendación. Veamos por ejemplo la llegada a Mendoza de Joan Corominas, recomendado por Ramón Menéndez Pidal desde París, donde se encontraba refugiado, y por Amado Alonso, en el Instituto de Filología de la Universidad de Buenos Aires. Se le hacía llegar al candidato la oferta de una cátedra junto con su respectivo salario y posibilidades de expansión y crecimiento en el cargo, y además, en el caso de la Universidad de Cuyo, el rector era muy cuidadoso en prestar atención a la orientación política del candidato. Acerca de la invitación a Corominas, Amado Alonso le escribió que:

Me dice el Dr. Ricardo Rojas que de la Universidad de Cuyo han enviado un telegrama para usted a Don Ramón Menéndez Pidal [...] que dice lo siguiente: «Hay [...] solamente una cátedra de lengua y otra de literatura españolas. Sueldo $\$ 600$, puesto que se le ofrece con tal de que no profese ideas extremistas». Tiene usted que contestar aceptando sin vacilar [...] Ya habían desistido de traerlo a usted, pues el Gobierno no quiere extranjeros, especialmente ni judíos ni españoles, pero la carta de Don Ramón ha cambiado las cosas ${ }^{36}$.

Las restricciones, sumamente difíciles de remontar en una época del más brutal antisemitismo, se podían remover sin embargo con contactos e influencia como se ve. Corominas aceptó el cargo, ocupó las cátedras prometidas entre 1940 y 1944 y además logró establecer el Instituto de Lingüística, pero se vio forzado a abandonar la Argentina porque el golpe militar de 1943 implicó el desplazamiento de Correas. Corominas reconocía el esfuerzo que se hizo en Mendoza por poner a punto la universidad regional, pero al mismo tiempo se lamentaba por sus falencias. Citamos en extenso sus impresiones puesto que al tratarse de la misma universidad que acogería a Sánchez Albornoz resultan de gran interés:

La Universidad empezó el curso pasado modestamente, pero en el actual cuenta ya con un presupuesto considerable. Se ha nombrado o contratado a un centenar de profesores, si bien hay que tener en cuenta que, además de las facultades de Filosofía y Letras y de Ciencias Económicas, la integran la escuela de Lenguas Vivas, una

35 Correas, 1997.

36 Carta de Amado Alonso a Juan Corominas, Buenos Aires, 14 de julio de 1939, en Pascual y Pérez Pascual, 2006: 99. 
de Bellas Artes, un Conservatorio de Música, un Instituto del Profesorado Secundario y sendas Escuelas de Agronomía, Normal de Maestros, de Minas y de Ingenieros. La tendencia local es a tener muchos profesores y a ver caras nuevas que a sacar todo el jugo de los buenos elementos con que ya se cuenta. Españoles por ahora no habrá más que tres entre tanta gente: [Manuel] Balanzat —un discípulo de [Julio] Rey Pastor-, yo y Sánchez Albornoz que, al parecer, va a llegar pronto.

[...] Compuse hace tiempo una lista de 300 volúmenes, con lo más necesario que falta a nuestra biblioteca [...] pero trabajé en balde porque nada se compró y con la lista no se hizo más que mandarla a Rafael Vehils [...] quien se había ofrecido a hacer un donativo de libros a la Universidad [...] Desprovisto de toda clase de medios de estudio, a 24 horas de tren de Buenos Aires, obligado a enseñar una materia tan árida y tan poco instructiva para mí como la gramática normativa, en un ambiente que en mi formación sólo admira lo más vulgar y elemental y ni por asomo comprende lo que más me ha costado y yo más estimo, y que generalmente lo que más aprecia en los catedráticos es la elegancia en el vestir y la facilidad de palabra, en las primeras semanas después de mi llegada me abrumó la sensación de tedio y desaliento al extremo de que escribí a D. Américo Castro que viera si me podía encontrar algún puesto en los EE.UU. [...] El Sr. [Amado] Alonso quiere convencerme de que pase en la Argentina el resto de mi vida; aunque no imposible, lo veo algo difícil. La caída para el estudioso que viene de Europa es demasiado grande ${ }^{37}$.

El panorama le resultaba, como se ve, poco estimulante. Tampoco los funcionarios de la FR se llevaron una muy buena impresión acerca de la Universidad de Cuyo, puesto que carecía de laboratorios y nutridas bibliotecas ${ }^{38}$. El acuerdo se sostuvo en pie, sin embargo, gracias al apoyo firme que desde Buenos Aires le brindó Rafael Vehils tanto a Sánchez Albornoz como a la propia Universidad de Cuyo, bajo Edmundo Correas. En efecto, Vehils desde Buenos Aires y Correas en Mendoza construyeron un estrecho vínculo que hizo posible - entre otras cosas - que el rector cuyano acariciara la idea de fundar una sede regional de la Cultural Española, con aval de la de la capital, además de recibir la ayuda de Vehils para gestionar la llegada de profesores: intentó infructuosamente llevar a los músicos Jaime Pahissa y Manuel de Falla pero en cambio logró que arribara el matemático Pedro Pi Calleja, en cuyo beneficio colaboró Vehils para acelerar sus trámites migratorios ${ }^{39}$. Correas invocaba la vocación hispanista e hispanoamericana de la Universidad Nacional de Cuyo («tiene un alma y una característica que la diferencian de todas las demás de América y probablemente del mundo entero: su predilección por los estudios

37 Carta de Joan Corominas a Ramón Menéndez Pidal, Mendoza, 23 de mayo de 1940, en Pascual y Pérez Pascual, 2006: 103-113.

38 Carta de L. W. Hackett a D. H. Stevens, Buenos Aires, 27 de septiembre de 1941, Archivos de la Fundación Rockefeller, Sleepy Hollow, RG 1.1 (FA 386), Box 7, Folder 78.

39 Telegrama de Edmundo Correas a Rafael Vehils, Mendoza, 1 de octubre de 1941, Archivo de ICEBA, Residencia de Estudiantes, Madrid, Correspondencia recibida 2, legajo 9, foto 611. 
hispanoamericanos $\rangle^{40}$ ) a fin de solicitar el apoyo de ICEBA para gestionar invitaciones a profesores españoles en el exilio, así como también para informarse de antecedentes de los posibles nombres que se invitarían. Por ejemplo, en 1939 le enviaba a Vehils el siguiente telegrama que muestra que la cuestión ideológica ocupaba un lugar importante en el tipo de antecedentes a considerar: «Ruégole enviarme mayores informes sobre condiciones personales como tendencias[,] carácter[,] ideología[,] etc. del profesor Jaime Pahissa» ${ }^{41}$. La preocupación de Correas por reclutar profesores exiliados, siempre que no hubieran tenido un pasado en el comunismo español, revela un gesto netamente conservador de su parte si bien no lo suficientemente radicalizado como para que sea posible hacerlo adscribir a una posición de corte nacionalista católica, de una hispanofilia reaccionaria; más bien, puede situárselo en un conservadurismo liberal que valora la herencia hispánica pero sin recaer en una idea cerril y reaccionaria de hispanidad, de ahí que lo podamos encontrar abriéndole las puertas a Sánchez Albornoz en 1940 a pesar de que se trataba de alguien que había trabajado para la Segunda República y se había expuesto públicamente en la Argentina como tal durante su viaje de $1933^{42}$. Ya vimos que Vehils tenía prevenciones con Sánchez Albornoz por su pasado republicano en un contexto donde las instituciones comunitarias españolas estaban tratando de acomodarse a los nuevos tiempos luego del triunfo de Franco. Así, pues, no ha de extrañar que a Sánchez Albornoz se le exigiera un estricto compromiso de «neutralidad política absoluta» para entrar a la Argentina a través de la universidad mendocina y de «abstenerse de actuar en otros centros culturales» ${ }^{43}$. La actitud de Correas, receptiva si bien con moderación, hizo posible que Sánchez Albornoz ingresara al país con el apoyo de Vehils que, desde Buenos Aires, colaboró en diferentes gestiones. Sánchez Albornoz quedó por demás agradecido: «No sé cómo agradecer a Ud. sus gestiones decisivas en el asunto de mi contrato por la Universidad de Cuyo. Cuente con mi gratitud de por vida» ${ }^{44}$.

40 Carta de Edmundo Correas a Rafael Vehils, Mendoza 29 de febrero de 1940, Archivo de ICEBA, Residencia de Estudiantes, Madrid, Correspondencia recibida 2, legajo 8, foto 803-4.

41 Telegrama de Edmundo Correas a Rafael Vehils, Mendoza, 6 de diciembre de 1939, Archivo de ICEBA, Residencia de Estudiantes, Madrid, Correspondencia recibida 2, legajo 7 , foto 157 .

42 Fares, http://historiapolitica.com/dossiers/dossierderechas/, consultado en enero de 2018.

43 Carta del rector Edmundo Correas a Rafael Vehils, Mendoza, 21 de mayo de 1940, Archivo de ICEBA, Residencia de Estudiantes, Madrid, Correspondencia recibida 2, legajo 8, foto $769-772$.

44 Carta de Claudio Sánchez Albornoz a Rafael Vehils, Caudéran, Bordeaux, 1 de junio de 1940, Archivo de ICEBA, Residencia de Estudiantes, Madrid, Correspondencia recibida 2, legajo 8 , foto 777 . 
Sobre esta base, a lo largo de 1940 se reiniciaron las tratativas con la FR pero no fue fácil lograr que la fundación norteamericana apoyara el traslado. Edmundo Correas escribió para consultar y recibió una larga carta de Irving Leonard, en nombre de la fundación, donde le explicaba que no se podía apoyar a Sánchez Albornoz si no se lo hacía según las reglas que la institución aplicaba en estos casos: la FR solo costearía un suplemento salarial por un plazo máximo de tres años, con el compromiso de la universidad que lo recibía de pagar el salario íntegro una vez cumplido ese plazo para así retener al investigador. De no cumplirse estas condiciones, la Rockefeller no haría nada. Correas, pues, debió revisar las condiciones que le ofrecía a Sánchez Albornoz y finalmente, el 24 de junio de 1940, llegó la confirmación de la FR de que lo apoyaría: «la subvención mencionada fue aprobada el 21 de junio de 1940 en el entendido de que estaría a la disposición de la Universidad Nacional de Cuyo con el fin de invitar al profesor Claudio Sánchez Albornoz, exprofesor de Historia Española en la Universidad de Madrid» ${ }^{45}$. La Fundación Rockefeller reconsideró a la luz de los acontecimientos de Francia el caso de Sánchez Albornoz y a pesar de las vacilaciones - hubo funcionarios de la FR que argumentaron que no sabían si hacían bien en concederle el subsidio dado el panorama de incertidumbre general y la débil posición de la universidad mendocina-, las oficinas centrales de Nueva York resolvieron que tomarían el caso de novo y aprobaron el financiamiento ${ }^{46}$.

La Universidad de Burdeos no puso objeciones; para ella era un alivio a esa altura de las circunstancias. Nada más quedaba resolver la cuestión de cómo se abonarían los gastos de viaje de su familia (su pareja y sus hijos) puesto que, como le confesaba Claudio Sánchez Albornoz a Vehils, le era difícil esperar ayuda de las organizaciones de apoyo a exiliados republicanos: «ni el SERE ni la JARE, de los que supongo habrá oído hablar, y que ayudan a los que fueron rojos a trasladarse a América, me dan un céntimo por mi postura independiente en la guerra civil»; al fin y al cabo, había dejado la península ibérica apenas iniciado el conflicto en $1936^{47}$. En este contexto, Sánchez Albornoz no vaciló en solicitar recursos adicionales para los traslados de su familia y, además, de sus materiales de trabajo y biblioteca, que incluían fichas, fotos de documentos y manuscritos: «No sé si todos vendrían por lo pronto conmigo; pero es muy

45 Carta de Irving Leonard a Edmundo Correas, 24 de junio de 1940, Archivo de ICEBA, Residencia de Estudiantes, Madrid, Correspondencia recibida 2, legajo 8, foto 780-781.

46 Special Research Aid Fund-European Scholars. Detailed information, New York, 31 de diciembre de 1940, Archivos de la Fundación Rockefeller, Sleepy Hollow, RG 1.1 (FA 386), Box 7, Folder 78.

47 Carta de Claudio Sánchez Albornoz a Rafael Vehils, Bordeaux, 6 de marzo de 1940, Archivo de ICEBA, Residencia de Estudiantes, Madrid, Correspondencia recibida 2, legajo 8, foto 686 . 
probable que sí. La conveniencia de solicitar la ayuda de la Embajada de la Argentina para poder llevar fácilmente a esa los materiales científicos» era algo para él imperativo, continúa. Fue Vehils, desde Buenos Aires, quien se encargó de agilizar trámites migratorios, gracias a los vasos comunicantes que existían entre la Institución Cultural Española y las elites políticas. En un contexto en el que, debido a las restricciones de las leyes migratorias argentinas se requería un «permiso de desembarco» para poder ingresar al país, mover influencias era un factor clave, capaz de abrir las puertas necesarias ${ }^{48}$. Sánchez Albornoz llegó solo a Buenos Aires — sus hijos volvieron a Ávila, España, y su pareja se demoró por problemas migratorios - en un sinuoso trayecto que fue de Marsella a Argel en barco, de Argel a Casablanca en tren, de Casablanca a Lisboa (donde había sido diplomático y todavía tenía contactos útiles en el régimen de Oliveira Salazar) en un pesquero, de Lisboa a Río de Janeiro en barco de línea portuguesa, de Río a Buenos Aires en uno de cabotaje ${ }^{49}$. La llegada a la Argentina fue posible gracias a gestiones llevadas a cabo en Francia por el embajador argentino Miguel Ángel Cárcano, lo cual muestra una vez más que los contactos de la ICEBA con las elites políticas fueron decisivos para sacar a Sánchez Albornoz de la Francia de Vichy, así como también fue crucial el apoyo de la FR para costear su boleto y demás gastos ${ }^{50}$. La Universidad de Cuyo, por su parte, le facilitó viáticos para sus gastos de instalación en Mendoza adonde arribó en diciembre de 1940.

\section{La Fundación Rockefeller una vez más. De Mendoza a Buenos Aires}

Apenas arribado a Mendoza, Sánchez Albornoz le escribió a Vehils en agradecimiento: «no olvidaré y no olvido su cariñosa ayuda para lograr llegar a este rincón del mundo donde vivir y continuar mis trabajos». También escribió las consabidas cartas de agradecimiento a la FR, si bien con un tono menos afectuoso. Pero su correspondencia no era tan entusiasta en líneas generales, puesto que agregaba: «no quiero ocultarle que me siento muy solo y tristón en estas lejanías [...] Temo dejarme dominar por el tedio y la depresión en estas soledades, lejos

48 Devoto, 2001.

49 Carta de Claudio Sánchez Albornoz a Mr. Makinsky (funcionario de la FR en Lisboa), 4 de octubre de 1940, Archivos de la Fundación Rockefeller, Sleepy Hollow, RG 1.1 (FA 386), Box 7, Folder 78. Agradezco a Nicolás Sánchez-Albornoz por la precisión en los datos.

50 Telegrama de Rafael Vehils dirigido a Edmundo Correas, Buenos Aires, 15 de octubre de 1940, Archivo de ICEBA, Residencia de Estudiantes, Madrid, Correspondencia recibida 2, legajo 8 , foto 789 . 
de España, de mis padres y de mis hijos, de los amigos de esa, sin conocer a nadie, sin urgencias de trabajos» ${ }^{51}$. Sin embargo, a juzgar por la labor desarrollada por Sánchez Albornoz en 1941, sería difícil afirmar que lo venció el tedio. En una universidad de tan reciente creación, puesto que había sido fundada en 1939, sin haber terminado de conformar aún su planta docente, la composición de sus cátedras y de sus institutos de investigación, Cuyo ofrecía algunas oportunidades: la posibilidad de trabajar en un ambiente receptivo, como ya se vio, a las humanidades y a los estudios hispánicos en general; la presencia de otros investigadores refugiados de diferentes latitudes; el hecho de que Mendoza contara con algunas publicaciones de interés general de fuerte trayectoria como es el caso del diario Los Andes, una tribuna que tenía amplia llegada en la ciudad de Buenos Aires donde Sánchez Albornoz se volcó a colaborar raudamente. Puesto que se trataba de una universidad donde todo estaba por hacerse, y donde no existía una elite académica enquistada en las cátedras, dada su jovencísima trayectoria, Cuyo le ofreció un ambiente fructífero de trabajo, si bien con fuertes limitaciones en la infraestructura, la capacidad de la biblioteca, lo escasamente dinámico del centro universitario dada la lejanía con otros centros culturales, editoriales y de producción académica. No obstante, Sánchez Albornoz no desaprovechó un segundo en su refugio mendocino: no solo publicó una quincena de artículos de divulgación y de opinión en el diario regional en un lapso de seis meses, entre enero y junio de 1941, sino que además sacó a luz un libro especializado que había sido prometido con anterioridad a su llegada a la Argentina y que se convertiría en uno de sus trabajos más reeditados: En torno a los orígenes del feudalismo, cuya primera edición fue hecha por la universidad mendocina en 1942. Por si fuera poco, en agosto de 1941, lograba concertar una visita a la Universidad de Buenos Aires con el aval del decano de la Facultad de Filosofía y Letras, el historiador Emilio Ravignani, para dictar un ciclo de tres conferencias, en una visita a la capital que aprovecharía para darse a conocer en los grandes diarios de Buenos Aires y además para conocer el ambiente académico porteño, sus posibilidades y limitaciones ${ }^{52}$. En 1942 debía renovar contrato con Cuyo; sondear el ambiente académico de Buenos Aires era pues muy importante.

Al cabo de pocas semanas, y ya de regreso a Mendoza, Sánchez Albornoz comenzaba a pensar en hacer realidad su anhelo de trasladarse definitivamen-

51 Carta de Claudio Sánchez Albornoz a Rafael Vehils, Plaza Mendoza Hotel, s/f, Archivo de ICEBA, Residencia de Estudiantes, Madrid, Correspondencia recibida 2, legajo 9, foto 533.

52 El programa incluía tres charlas: "Cómo nace un pueblo. Castilla revolucionaria y separatista", "Castilla, un pueblo sin burguesía”, "Castilla hizo a España y España deshizo a Castilla". Archivo de ICEBA, Residencia de Estudiantes, Madrid, Correspondencia recibida 2, legajo 9, foto 277 . 
te a Buenos Aires, para lo cual comenzó a escribir cartas con la expectativa de mover influencias. Volvió, pues, a escribirle a Rafael Vehils. No había transcurrido todavía un año de su llegada al país y proponía todo un plan de reestructuración de cátedras del área de Historia Antigua y Medieval, que haría posible su arribo a la Universidad de Buenos Aires:

Perdone que moleste su atención con el ruego de que vea a [Coriolano] Alberini y a Ravignani y quizá al nuevo Rector [v. g., Carlos Saavedra Lamas] que Ud. conoce desde hace tiempo. La situación de esta Universidad [de Cuyo] es harto inestable. Está condenada a una poda importante. La Facultad de Letras, según lo más probable, va a ser trasladada a San Luis. Compadézcase de mí. Ya mi estadía en Mendoza me impedía la prosecución de mis investigaciones históricas. ¿Qué voy a hacer en San Luis? Si Saavedra Lamas, Alberini y Ravignani quieren, mi incorporación a la Universidad de Buenos Aires puede ser inmediata. [Alberto] Freixas ha sido o va a ser profesor en la vacante de [historiador italiano Clemente] Ricci [se retiró en 1941 y falleció en 1946]. Pero éste era profesor de dos disciplinas: Historia antigua y media e Historia de las religiones. Apartado él de la enseñanza, no tiene razón de subsistir la cátedra de Historia de las religiones. Su dotación podría aplicarse para segregar de la Historia antigua y media, está última. Freixas ha trabajado en Historia antigua, pero no en Historia medieval. En todas partes están separadas las dos enseñanzas. Tienen a mano un hombre, modesto, pero que ha consagrado su vida a la Historia de la Edad Media. ¿Por qué no aprovecharle? Los Rockefeller ayudarán, como a Mendoza, durante el año 42 y luego la Universidad de Buenos Aires podría tomar a su cargo la dotación plena, creando un Seminario o un Instituto de Historia medieval. Tengo conmigo materiales para hacer una enseñanza eficiente para instruir a los alumnos en el conocimiento de la Paleografía y Diplomáticas medievales. He traído los millares de fichas que había reunido para mi Historia de los Orígenes de las Instituciones Castellanas. [...] Tengo terminado el libro que me publica la Universidad de Cuyo sobre el Feudalismo. [...] El año que viene acabaré el comprometido con usted. [...] Podría ir publicando cada año un libro y colaborar activamente en la Revista de la Facultad.

¿Quién puede llevar a una cátedra de la Facultad labor parecida? Apriételes. Me aterra la idea de ir a San Luis. [...] Sólo en Buenos Aires puedo trabajar. Hay libros en las Facultades de Derecho y de Letras y en otras bibliotecas. Entre esos libros y los míos y mis papeles, puedo continuar mis investigaciones. Puede Ud. mucho y es Ud. — gran diplomático — si quiere... Y a Buenos Aires podría traer a mis hijos. [...] ¿La Cultural no se decidiría a crear una cátedra de Historia de España? ¿Hasta cuándo va a enseñarse Historia de Francia, de Italia o de Inglaterra en la Argentina y no se va a poder oír hablar de Historia de España?53

Una vez que trazó tan ambicioso plan, que comprendía el desdoblamiento de una cátedra de la Universidad en la que Sánchez Albornoz carecía de in-

53 Carta de Claudio Sánchez Albornoz a Rafael Vehils, Mendoza, 10 de octubre de 1941, en Archivo de ICEBA, Residencia de Estudiantes, Madrid, Correspondencia recibida 2, legajo 9 , foto $530-532$. 
fluencia, sumado a la operación de traslado del subsidio internacional que le proporcionó la FR y la potencial creación de una cátedra de Historia de España avalada por la ICEBA, cuya mediación solicitaba una vez más, tan solo cabía aguardar la respuesta de su amigo catalán en Buenos Aires. Vehils no desoyó el pedido y siguió exactamente la estrategia sugerida por Sánchez Albornoz. Se conserva en el archivo de la ICEBA copia de una carta que habría dirigido a las autoridades universitarias, entre ellas, seguramente, Emilio Ravignani, decano de la Facultad de Filosofía y Letras:

El Dr. Claudio Sánchez Albornoz desearía incorporarse en alguna forma a la Universidad de Buenos Aires [...] sugiere la creación de una cátedra de Historia Medieval o de Historia de España o un Seminario consagrado a estas materias asignándole la dotación que tenía destinada a la Historia de las Religiones mientras el Prof. Ricci dictó esa cátedra. El Prof. Albornoz cree que la Institución Rockefeller contribuiría al sostenimiento de su cátedra durante $1942^{54}$.

Sobre esta propuesta, las tratativas avanzaron, si bien con algunas limitaciones. En enero de 1942, Sánchez Albornoz le escribía nuevamente a Vehils en los siguientes términos:

Agradezca en mi nombre a Ravignani cuanto haga. Comprendo todas las dificultades. Pero ellos deben comprender que tienen en sus manos la posibilidad de introducir una enseñanza y una investigación nueva en la Argentina y en América. Me han dicho que de Estados Unidos vinieron a Buenos Aires unos estudiantes a trabajar en el período carolingio y, claro, tuvieron que volverse a Norte América. $\mathrm{Y}$ es precisamente el período que trabajo. [...] Escribiré a los Rockefeller. Mejor dicho, a Buenos Aires, al representante de la Fundación allá. Pero mi carta parecerá interesada y no tendrá eficacia. La tendría la de U., como Pr.[esidente] de la Cultural. Aunque no fuere sino de sondeo y tanteo, sin compromiso alguno. [...] ¿Por qué no le telefonea U. y charla con él? Se llama Dr. Lewis Wendell Hacket, director regional de la F. R. en B.A. [...] Ha estado en Mendoza [...] visto mis materiales y fotos y fichas y elementos y quedó bien impresionado. Creo que será fácil moverle a informar a Nueva York. Con él estuvo uno de los altos funcionarios de la Fundación que me prometió hablar a Nueva York. Pero no olvide que los R. no me ayudarán sino este año de 1942. Quizá si la Facultad y la Cultural [...] propusieran a Nueva York la creación de un Instituto de Estudios Medievales en Buenos Aires, aprovechando mi presencia aquí, podrían lograr el apoyo de la fundación. Creo que podría hacer labor útil, útil para la ciencia argentina y para el nombre de España ${ }^{55}$.

54 Borrador de carta, s/d, Archivo de ICEBA, Residencia de Estudiantes, Madrid, Correspondencia recibida 2, legajo 9, foto 542 .

55 Carta de Claudio Sánchez Albornoz a Rafael Vehils, Mendoza, 4 de enero de 1942, en Archivo de ICEBA, Residencia de Estudiantes, Madrid, Correspondencia recibida 2, legajo 10 , foto $797-8$. 
El médico Wendell Hackett se encontraba en la región meridional de América del Sur desde 1941, cuando la FR instaló sus oficinas en la región con el propósito de prevenir, tratar y alentar la capacitación entre médicos y enfermeras en enfermedades tropicales tanto en la Argentina como en Chile y otros países, así que no es de extrañar encontrarlo viajando por Mendoza en esta época ${ }^{56}$. El contacto que Sánchez Albornoz hizo con un alto funcionario de la FR debió haber sido de gran ayuda en el propósito de trasladar su vida académica a Buenos Aires puesto que no hubo reparo alguno esta vez por parte de la fundación norteamericana para la propuesta dado que no modificaba las condiciones ni los plazos acordados en 1940 cuando se trasladó a Mendoza, sino únicamente la institución que lo acogería y las facilidades que de ella obtendría. Como la Universidad pública se regía por el presupuesto nacional, que se decidía por el Congreso con un año de antelación, no podía tomar decisiones en tan corto plazo en materia de nombramientos y partidas presupuestarias; por ello, se hizo necesario un acuerdo tripartito que se gestionó entre la ICEBA, la FR y la propia universidad. Como explicaría Hackett a los funcionarios de la FR en Estados Unidos, el problema se presentaba del siguiente modo:

Es tarde para colocarlo a él o al Instituto en el presupuesto universitario de... 1942. Albornoz apeló a la Institución Cultural Española que está deseosa de contribuir con la misma parte de su salario (400 pesos) pagado por la Universidad de Cuyo dado que la FR transferirá su ayuda de 400 pesos mensuales a la Universidad de Buenos Aires.[...] La ICEBA y la Universidad continuarán ayudándolo en la misma proporción en 1943 si la Fundación continúa con sus pagos mensuales y en 1944 la Universidad asumirá el salario completo de Albornoz y mantendrá el Instituto [de Historia Medieval] ${ }^{57}$.

La FR además ayudó con gastos para adquisición de bibliografía y copias de materiales de archivo para la nueva biblioteca, mientras que la Universidad de Buenos Aires se comprometió, durante los primeros dos años, con un módico pago mensual. Se le exigió que ejerciera tanto la cátedra de Historia medieval como la puesta en marcha de un Instituto de investigación de Historia de la Cultura Española Medieval y Moderna, que la ICEBA por su parte se dispuso a apadrinar:

56 Ramacciotti, 2017. La FR también tuvo estrechos vínculos con la medicina española. Véase al respecto Barona et al., 1998. Sobre su presencia en América Latina, véase Morcillo Laiz, 2019. Parmar, 2012. Levy, 2005.

57 Carta de L. W. Hackett a D. H. Stevens, Buenos Aires, 6 de abril de 1942, Archivos de la Fundación Rockefeller, Sleepy Hollow, RG 1.1 (FA 386), Box 7, Folder 72. 
La Facultad crea el Instituto con carácter permanente, de manera que lo incorpora a sus actividades en la misma forma que los demás institutos. Como contribución inicial por este año [1942] le asignará al director la suma de 200 pesos mensuales, más los gastos de instalación y local. Es lo que tienen asignado otros directores de la categoría B. Si el trabajo progresa se crearé en el año próximo la cátedra que con la dotación correspondiente le significará al director y profesor 575 pesos mensuales. Es propósito de la Facultad ofrecerle al doctor Sánchez Albornoz un contrato por tres años como mínimo [...] Me he informado de la respuesta de la Rockefeller. [...] Lo que considero difícil es que la Universidad de Cuyo quiera renunciar a ello ${ }^{58}$.

El obstáculo que refiere no fue de envergadura puesto que apenas dos días después Hackettt le decía a Ravignani que no solo quedaba el terreno allanado dado que el rector cuyano había dado su anuencia, sino que además garantizaba con amplia generosidad que Sánchez Albornoz pudiera instalarse en la Universidad de Buenos Aires puesto que se le prometía extender el subsidio de la fundación norteamericana por un año más de lo que el propio Sánchez Albornoz habría imaginado:

He recibido hoy una carta del Sr. Edmundo Correas, rector de la Universidad Nacional de Cuyo que dice lo siguiente: «Tengo el agrado de dirigirme a Ud. para poner en conocimiento que esta Universidad no tiene inconveniente en que el Dr. Claudio Sánchez Albornoz se incorpore a la Universidad de Buenos Aires y, en consecuencia, se transfiera el subsidio que recibe el mencionado Profesor». En vista de esto, estoy autorizado por el director de la División de Humanidades de la fundación Rockefeller para informarle que la Fundación está dispuesta a transferirle el subsidio $400 \$$ mensual para el salario del profesor Sánchez-Albornoz a la Universidad de Buenos Aires en las mismas condiciones a las que gobernaban el mismo subsidio a la Universidad de Cuyo. Tenemos entendido que se obtendrían fondos de otra fuente para proveer un salario de por lo menos $800 \$$.

También estoy autorizado a transmitirle que es probable que una solicitud para ayuda continuada en las mismas condiciones para el año 1943, como también para un pequeño subsidio para la biblioteca del Profesor Sánchez-Albornoz, recibirá una favorable acogida por parte de la fundación Rockefeller [...] Es nuestro entendimiento que en el año 1944 y los años subsiguientes la Universidad continuará su mantenimiento del Instituto de Historia de la Cultura Española Medieval y Moderna y pagará un sueldo al profesor Sánchez-Albornoz igual o superior a lo establecido en el acuerdo citado ${ }^{59}$.

58 Carta de Emilio Ravignani a Rafael Vehils, Buenos Aires, 22 de abril de 1942, en Archivo de ICEBA, Residencia de Estudiantes, Madrid, Correspondencia recibida 2, legajo 10, foto 338 .

59 Carta de L. W. Hackett a Emilio Ravignani, 24 de abril de 1942, en Archivo de ICEBA, Residencia de Estudiantes, Madrid, Correspondencia recibida 2, legajo 10, foto 339. 
El proyecto del Instituto fue puesto en marcha por resolución del decanato de la Facultad de Filosofía y Letras en abril de 1942, con el objeto de alentar la investigación, la edición de publicaciones periódicas sobre cultura española medieval y moderna, el dictado de cursos y la conformación de una biblioteca especializada. Las gestiones fueron algo más lentas de lo que el medievalista hubiera deseado, pero llegaron a buen puerto: en el acto de inauguración, celebrado el 20 de octubre de 1942, el historiador pronunció la conferencia «León y Castilla, islote de hombres libres hace mil años», que contó con la presencia de las autoridades de la Facultad y de la ICEBA. En diciembre, a continuación, se formalizó la firma del contrato por tres años (con posibilidad de renovación) con la Universidad de Buenos Aires, en las siguientes condiciones: se lo contrató para dirigir el Instituto de Historia de la cultura Española Medieval y Moderna, creado en mes de abril de 1942, y además se le asignó la cátedra de Historia de España Medieval y Moderna, creada por resolución de noviembre de 1942, por tres años, desde el 1 de enero de 1943, con un sueldo (finalmente) de mil pesos. «Este sueldo le será liquidado y pagado mensualmente desde el primero de enero de 1943 y hasta el 31 de diciembre de 1945, integrándose con el aporte del presupuesto a universitario y las donaciones de la fundación Rockefeller y de la Institución Cultural Española» ${ }^{60}$.

El papel de la Rockefeller fue decisivo para poder realizar el traspaso, previa anuencia de la Universidad de Cuyo que no puso traba alguna, así como también para facilitar la puesta en marcha del nuevo Instituto en Buenos Aires y adquirir bibliografía especializada, para lo que ofreció un monto extra de mil dólares. No menos importante fue, por otro lado, la colaboración de la ICEBA a través de su director, Rafael Vehils. No solo porque Vehils se preocupó por Sánchez Albornoz y le sirvió de respaldo en cada ocasión que necesitara, desde la salida de Francia o su aterrizaje en la Universidad de Buenos Aires. Vehils fue más lejos incluso, dado que a través de la ICEBA hizo un donativo extraordinario al flamante instituto de investigación para facilitar su puesta en marcha por 2400 pesos argentinos ${ }^{61}$. De tal modo que era justo que ambas instituciones, la fundación norteamericana y la entidad comunitaria argentina, fueran mencionadas a la par en el contrato de Sánchez Albornoz. Vehils además le facilitó distintas gestiones a Sánchez Albornoz para su instalación, en especial, en todo aquello que tenía que ver con la ad-

60 Contrato celebrado con el profesor Dr. Claudio Sánchez Albornoz, expediente 5040/1942, Archivo del Rectorado de la Universidad de Buenos Aires.

61 Carta de Emilio Ravignani a Rafael Vehils, 12 de agosto de 1942, Archivo de ICEBA, Residencia de Estudiantes, Madrid, Correspondencia recibida 2, legajo 10, foto 783. 
quisición de libros de origen español. Como además Sánchez Albornoz le prometió a Vehils la preparación de un libro para su publicación por ICEBA, aprovechó la ocasión para solicitarle gestiones al respecto:

Le ruego que escriba a España como Presidente de la Cultural anunciando la creación del Instituto y pidiendo que envíen sus publicaciones de $\mathrm{H}$ [istori]a Medieval — dejemos por ahora las modernas - a la Academia de la H, la Junta de Ampliación [de Estudios] o su sucedánea [...] Tengo amigos en todas partes, comprenderán y enviarán. [...] Algún librero podrá enviar - pagando el Instituto o yo- algunas obras que me son de gran necesidad ${ }^{62}$.

Una vez instalado en Buenos Aires y con la perspectiva de continuar adelante con su labor científica a pesar del contexto adverso - con el régimen de Franco instalado en el poder en España, sumado a la amenaza nazi y al deterioro del sistema político en Argentina que en 1943 desembocaba en un golpe militar inspirado en valores nacionalistas y católicos- Sánchez Albornoz no pudo sino sentirse agradecido:

Hubiera querido agradecerle, otra vez, la ayuda de la Cultural a la institución naciente. Sin ella y sin la iniciativa de Ud. no hubiera sido creado el nuevo centro. Es raro hallar en estos tiempos español como Ud. y agrupación como la Cultural, que por encima de toda cuestión ideológica estén siempre decididos a apoyar toda empresa científica de importancia, cualquiera que sea la persona que pueda acometerla. Sin Ud., a estas horas estaría aún en Francia, si es que no había sido entregado a Franco y encarcelado o fusilado. Gracias a Ud. y a la Cultural se arregló mi cátedra de Mendoza y ahora me ayudan a venir a Buenos Aires a proseguir mis trabajos con dignidad y libertad plenas. Muchas gracias desde el fondo de mi alma. Acá tengo libros y materiales. Los Rockefeller - a quienes no debo menor gratitud y que al igual que la Cultural me han traído a América y a Buenos Aires - van a permitirme con su ayuda adquirir nuevos materiales ${ }^{63}$.

El agradecimiento de Sánchez Albornoz era mucho más cálido con Vehils y con la ICEBA que con la FR, con la que siempre tuvo un trato relativamente distante, en parte porque las gestiones con la FR solían llevarlas las instituciones universitarias antes que el propio interesado, en parte también por la distancia cultural con una institución como la FR que encarnaba la sociedad norteamericana y sus valores. Con el tiempo Sánchez Albornoz incluso llegó

62 Carta de Claudio Sánchez Albornoz a Rafael Vehils, 22 de noviembre de 1942, Archivo de ICEBA, Residencia de Estudiantes, Madrid, Correspondencia recibida 2, legajo 10, foto 811-814.

63 Carta de Claudio Sánchez Albornoz a Rafael Vehils, Buenos Aires, octubre de 1942, Archivo de ICEBA, Residencia de Estudiantes, Madrid, Correspondencia recibida 2, legajo 10 , foto 841 . 
a borrar de su relato la ayuda norteamericana, dejando en pie únicamente la mención al empresario catalán: «siempre reconozco mi deuda con el presidente de la Cultural Española de entonces, Rafael Vehils. La Cultural me trajo a la Argentina» ${ }^{64}$, dirá años después como si la Fundación Rockefeller no hubiera jugado ni siquiera el más ínfimo papel. El reconocimiento a la Fundación Rockefeller está en cambio presente en su hijo, también historiador, Nicolás Sánchez Albornoz ${ }^{65}$, quien omite por otra parte mencionar a la ICEBA que, si bien con menos recursos económicos que la fundación norteamericana, tal vez, supo mover influencias y hacer gestiones - algunas imprescindibles, otras simplemente como gesto de buena voluntad para facilitar las cosas al exiliado-, además de brindar apoyo económico. En una u otra versión de los hechos es posible que se trasluzcan empatías o antipatías con los Estados Unidos, y quizás algún tipo de regusto revelador de un sentimiento nacional, pero para el caso no importa porque lo que nos interesa mostrar a través del caso de Claudio Sánchez Albornoz es que el exilio científico republicano español trasciende las fronteras y debe ser leído en perspectiva amplia, atlántica e hispanoamericana.

\section{CONCLUSIÓN}

La excepcionalidad del caso de Sánchez Albornoz en tanto que experiencia del exilio científico republicano se funda en las siguientes condiciones. Por un lado, el hecho de que la FR le haya brindado su protección en tres ocasiones diferentes, en países y universidades distintas según los casos, algo que no era habitual en sus procedimientos de ayuda a refugiados. Puede verificarse en los propios archivos de la FR que sus funcionarios juzgaron, en efecto, como excepcional este caso y estuvieron dispuestos a reconsiderarlo cuando se preparó la etapa argentina de su exilio. En segundo lugar, debe destacarse el hecho de que no recibió ayuda de organismos oficiales, gubernamentales o políticos; ni el gobierno argentino ni el francés participaron en las gestiones para darle acogida a su llegada. En tercer lugar, tampoco lo hicieron los diferentes organismos de ayuda humanitaria dirigida a refugiados que se implementaron para atender a los exiliados republicanos. La neutralidad del gobierno argentino supuso indiferencia, cuando no hostilidad, para con los republicanos españoles la cual solo pudo ser sorteada a fuerza de amistades conspicuas entre las elites académicas, políticas o empresariales. Ya hemos visto que en este aspecto Sánchez

\footnotetext{
64 Caja de Ahorros de Asturias, 1980: 27, citado en Rodríguez Temperley, 2015.

65 Sánchez Albornoz, 2012.
} 
Albornoz tenía todas las cartas a su favor y que su relación con Vehils potenció sus posibilidades de ser acogido en la Universidad de Buenos Aires. Pero esta solamente le abrió sus puertas una vez que Sánchez Albornoz ya había ingresado a la Argentina para trabajar en Mendoza: así, la Universidad de Buenos Aires no rompió su política de neutralidad puesto que no lo acogió como refugiado republicano sino como un profesor proveniente de una universidad periférica del país que ascendía en su carrera.

\section{BIBLIOGRAFÍA}

Albert Robatto, Matilde, Federico de Onís: cartas con el exilio, A Coruña, Ediciós do Castro, 2002.

Alted, Alicia y Domergue, Lucienne, El exilio republicano español en Toulouse, 1939-1999, Madrid, UNED y Presses Universitaires du Mirail, 2003.

Alted Vigil, Alicia y González Martell, Roger, "Científicos españoles exiliados en Cuba", Revista de Indias, LXII/224 (Madrid, 2002): 173-194. https://doi. org/10.3989/revindias.2002.i224.463

Appleget, Thomas, The Foundation's experience with refugee Scholars, Rockefeller Foundation, 1946.

Barona, Josep Lluís, El exilio científico republicano, Valencia, Universidad de Valencia, 2010.

Barona, Josep Lluís, Rodríguez, Esteban y Bernabeu-Mestre, Josep, "La Fundación Rockefeller y España, 1914-1939: un acuerdo para la modernización científica y sanitaria”, Juan Luis García Hourcade, Juan M. Moreno Yuste y Gloria Ruiz (coords.), Estudios de historia de las técnicas, la arqueología industrial y las ciencias, Junta de Castilla y León, 1998: 531-540.

Caja de Ahorros de Asturias, Homenaje de Asturias a Claudio Sánchez Albornoz, Oviedo, 1980.

Carzolio, María Inés, "L'histoire de Moyen âge en Argentine: Claudio Sánchez Albornoz et ses disciples", Bulletin du Centre d'Etudes Médiévales, 7 (Auxerre, 2007). https://doi.org/10.4000/cem.3222

Claret Miranda, Jaume, El atroz desmoche: la destrucción de la universidad española por el franquismo 1936-1945, Barcelona, Crítica, 2006.

Correas, Jaime, "Edmundo Correas, la contradicción civilizadora", Todo es Historia, 358 (Buenos Aires, 1997): 78-81.

Dalla-Corte Caballero, Gabriela, "Asociaciones y redes sociales entre El Quijote y Hamlet: la Casa de América de Barcelona y la construcción de una moderna fraternidad transatlántica", Boletín Americanista, 55 (Barcelona, 2005): 55-77. 
De Diego, José Luis, "La literatura latinoamericana en el proyecto editorial de Losada", La otra cara de Jano. Una mirada crítica sobre el libro y la edición, Buenos Aires, Ampersand, 2015: 141-164.

De Riquer, Borja, Cambó en Argentina. Negocios y corrupción política, Barcelona, Edhasa, 2016.

Devoto, Fernando, "El revés de la trama: políticas migratorias y prácticas administrativas en la Argentina", Desarrollo Económico, 41/162 (Buenos Aires, 2001): 281-304.

Devoto, Fernando, "Claudio Sánchez-Albornoz y el Anuario de Historia del Derecho español”, Cuadernos de Historia de España, 77 (Buenos Aires, 2001-2002): 225-231.

Díaz-R. Labajo, María Aránzazu, El exilio científico republicano en la Argentina. Contribuciones de los médicos, biomédicos y psicoanalistas españoles en la ciencia argentina (1936-2003), Salamanca, Ediciones Universidad de Salamanca, 2016.

Fares, María Celina, "Diferencias y convergencias en los hispanismos mendocinos. A propósito del sesquicentenario", Patricia Orbe (ed.), El nacionalismo argentino durante la segunda mitad del siglo $X X$, en línea en http://historiapolitica.com/ dossiers/dossierderechas/, consultado en noviembre de 2017.

Fernández Terán, Rosario E. y González Redondo, Francisco A., "Las cátedras de la Institución Cultural Española. Ciencia y educación entre España y Argentina, 1910-1940", Historia de la educación, 29 (Salamanca, 2010): 195-219.

Fink, Carole, Marc Bloch. Una vida para la historia, Valencia, Universidad de Valencia, 2004.

García Camarero, E., “La ciencia española en el exilio de 1939”, José Luis Abellán (ed.), El exilio español de 1939, Madrid, Taurus, 1976: 145-243.

Gemelli, Giuliana, The Unacceptables. American Foundations and Refugee Scholars between the Two Wars, Lovaina, Euroclio, 2000.

Guiance, Ariel, “Introducción. Las relaciones historiográficas entre España y América: un panorama de aportes y contradicciones", La influencia de la historiografía española en la producción americana, Valladolid, Marcial Pons, 2011.

Herrerín López, Ángel, "Las políticas de ayuda y de evacuación de los refugiados españoles en Francia durante la ocupación nazi", Cahiers de Civilisation Espagnole contemporaine, 9 (Angers, 2012). https://doi.org/10.4000/ccec.4287

Jensen, Silvina, "Los expatriados catalanes en Chile y Argentina y el universo de la ayuda solidaria hacia las víctimas de la guerra civil española", Projéto Historia, 52 (São Paulo, 2015): 37-75.

Krohn, Claus-Dieter, Intellectuals in Exile. Refugee Scholars and the New School of Social Research, The University of Massachusetts Press, 1993. 
Lamberti, Marjorie, "The reception of Refugee Scholars from Nazi Germany in America. Philanthropy and Social Change", Jewish Social Studies, XII/3 (Stanford, 2006): 157-192. https://doi.org/10.1353/jss.2006.0028

Levy, Daniel C., To Export Progress: The Golden Age of University Assistance in the Americas, Bloomington, Indiana University Press, 2005.

Lida, Clara E., Inmigración y exilio. Reflexiones sobre el caso español, México, El Colegio de México-Siglo XXI, 1997.

Lida, Clara E., Caleidoscopio del exilio. Actores, memoria e identidades, México, El Colegio de México, 2009.

Lida, Clara E. y Matesanz, José E., El Colegio de México: una hazaña cultural (19401962), México, El Colegio de México, 1990.

López Sánchez, José María, "La Junta para Ampliación de Estudios y su proyección americanista: la Institución Cultural Española en Buenos Aires", Revista de Indias, LXVII/239 (Madrid, 2007): 41-55. https://doi.org/10.3989/revindias.2007.i239.593

López Sánchez, José María, Los refugios de la derrota. El exilio científico e intelectual republicano de 1939, Madrid, CSIC, 2013.

Lucci, Marcela, "Edición y editores catalanes en Buenos Aires: una aproximación a la perspectiva de la gestión editorial a partir de la revista Ressorgiment", Nuevos Mundos/Mundos Nuevos, (París, 2016). https://doi.org/10.4000/nuevomundo.69351

Mendlesohn, Farah, Quaker Relief Work in the Spanish Civil War, New York, The Edwin Mellon Press, 2002.

Morcillo Laiz, Álvaro, "La gran dama: Science patronage, the Rockefeller Foundation and the Mexican Social Sciences in the 1940s", Journal of Latin American Studies, LI/4 (Cambridge, 2019): 829-854. https://doi.org/10.1017/s0022216x19000336

Naranjo Orovio, Consuelo, Cuba, otro escenario de lucha. La guerra civil y el exilio republicano español, Madrid, CSIC, 1988.

Naranjo Orovio, Consuelo, "Los caminos de la JAE en América Latina: redes y lazos al servicio de los exiliados republicanos", Revista de Indias, LXVII/239 (Madrid, 2007): 283-306. https://doi.org/10.3989/revindias.2007.i239.600

Naranjo Orovio, Consuelo y Puig Samper, Miguel Ángel, "Las redes de la ciencia: la JAE en el exilio", Asclepio. Revista de Historia de la Medicina y de la Ciencia, LIX/2 (Madrid, 2007): 231-254. https://doi.org/10.3989/asclepio.2007.v59.i2.239

Pagni, Andrea, El exilio republicano español en México y la Argentina. Historia cultural, instituciones literarias, medios, Madrid, Iberoamericana Vervuert, 2011.

Parmar, Inderjeet, The Ford, Carnegie and Rockefeller Foundations in the rise of American Power, Columbia University Press, 2012.

Pascual, José A. y Pérez Pascual, José Ignacio, Epistolario Joan Coromines \& Ramón Menéndez Pidal, Barcelona, Fundación Pere Coromines, 2006. 
Ramacciotti, Karina, "La Fundación Rockefeller y la división internacional de Salud en el Río de la Plata y la región andina: ideas, concreciones y obstáculos (19411949)", Redes. Revista de Estudios Sociales de Ciencia, 23/45 (Buenos Aires, 2017): 97-121.

Rodríguez Temperley, María Mercedes, "Lo que guardan los libros: la biblioteca de Don Claudio Sánchez Albornoz", Estudios de Historia de España, 17 (Buenos Aires, 2015): 225-246.

Sánchez Albornoz, Nicolás, "La Fundación Rockefeller y los exiliados españoles", Historia 16, 216 (Madrid, 1994): 116-120.

Sánchez Albornoz, Nicolás, Cárceles y exilios, Barcelona, Anagrama, 2012.

Schwarzstein, Dora, Entre Franco y Perón. Memoria e identidad del exilio republicano español en Argentina, Barcelona, Crítica, 2001.

Terracini, Lore, "Una inmigración muy particular: 1938, los universitarios italianos en Argentina", Anuario del IEHS, 4 (Tandil, 1989), pp. 335-369.

Velázquez Hernández, Aurelio, Empresas y finanzas del exilio. Los organismos de ayuda a los republicanos exiliados en México, México, El Colegio de México, 2014.

Fecha de recepción: 18 de enero de 2018.

Fecha de envío de las modificaciones: 12 de marzo de 2018.

Fecha de aceptación: 11 de mayo de 2018.

\section{The role of the Rockefeller Foundation and the Spanish Cultural Institution of Buenos Aires with regard to the Spanish republican exile in Argentina. The case of Claudio Sánchez Albornoz}

The Republican Scientific Exile to the Americas has been widely studied. In this context, the case of historian Claudio Sánchez Albornoz was quite exceptional because of the complex strategy that led to his arrival in Argentina. He was supported by the Rockefeller Foundation $(R F)$, whose role has barely been studied. Another key player was the Institución Cultural Española de Buenos Aires (ICEBA). Thanks to the archives at Buenos Aires University and $I C E B A$ (and correspondence with the RF), we can trace the network that made his arrival in Argentina possible, with the support of both institutions.

Key words: Spanish Scientific Republican Exile; Argentina; Claudio Sánchez Albornoz; historiography. 